\title{
Person-Centered Approach to the Diverse Mental Healthcare Needs During COVID 19 Pandemic
}

\author{
Sujita Kumar $\operatorname{Kar}^{1}$ (D) $\cdot$ Nitika Singh ${ }^{1}$
}

Accepted: 21 July 2020 / Published online: 15 August 2020

(C) Springer Nature Switzerland AG 2020

\begin{abstract}
In this COVID-19 pandemic, many mental health problems arose. The mental health difficulties are sufficiently significant to disturb the peace and wellbeing of the people involved. A poor population's mental health needs are complex (elderly individuals, those with chronic co-morbidity, youth and disadvantaged population, emergency care professionals, police officers, and patients with pre-existing mental health issues). In resource-scarce environments, in the light of the person-centered treatment paradigm, there is an immediate need to plan to meet the emerging challenge.
\end{abstract}

Keywords COVID-19 · Mental illness · Person-centered care

To the Editor,

The situation around the world is alarming. Worldwide, the future of such a pandemic is of concern to everyone, given the exponential increase in morbidity and mortality due to it. The anxieties and concerns about this outbreak of coronavirus have various implications for different population groups. The mortality and cases of infection are extreme in certain countries, whereas emerging slowly in many others. There is an ongoing worldwide debate on "whether the COVID 19 pandemic will generate a global preparedness?" [4]. The mental health challenges during the post-pandemic era may be diverse and intense, for which there is a need for global preparedness [2]. Figure 1 below depicts the various population groups along with their mental health concerns.

The pandemic has made clinical patient care tougher and has uncovered many pathologies right under the surface. During this pandemic, the general population is mostly homebound, whereas individuals who have contacted coronavirus infection (but are currently negative in the testing) and those

This article is part of the Topical Collection on Covid-19

Sujita Kumar Kar

drsujita@gmail.com

Nitika Singh

nitikasingh57@gmail.com

1 Department of Psychiatry, King George's Medical University, Lucknow, U.P, India who are already infected are forced to stay in hospital isolation [6]. The healthcare workers are regularly delivering the healthcare facilities and are returning home after work, as a result of which they are acting as a connecting link between hospital and community setting. This could probably intensify their fear of contracting the infection and transmitting it to their closed ones as well as to others [8]. The shortage of protective equipment is another matter of concern for healthcare workers [1]. The amount of distress among the healthcare professionals also vary. Adequate organizational support to the healthcare workers may be beneficial to curtail the major part of their distress [12].

There is a dire need for mental healthcare of the patients, particularly those who are infected with coronavirus and those who have come in contact with infected persons but are currently found negative in the investigation. Family members of the infected persons and the general population could also benefit from the variety of interventions that could be provided by the mental healthcare professionals [3]. A recently conducted study has revealed a perceived mental healthcare need among the general population. More than $80 \%$ of the participants had felt the need for seeking mental healthcare professionals. [9]. Unfortunately, mental health needs are not being adequately addressed worldwide. In the present state of acute crisis, shortage of manpower, resources, and infrastructure have posed a huge global challenge. Also, the patients who are already suffering from any psychiatric illness are unable to avail consultations for 
Fig. 1 Specific community mental health needs during corona pandemic

\begin{tabular}{|c|c|}
\hline General population & $\begin{array}{l}\text { - Fear of getting infected } \\
\text { - Loss or restriction of job related activities } \\
\text { - Restriction of social contact } \\
\text { - Exhaustion of resources (products of daily need, health care products) }\end{array}$ \\
\hline Healthcare workers & $\begin{array}{l}\text { - All the concerns of general population } \\
\text { - More intense fear of contacting infection }\end{array}$ \\
\hline $\begin{array}{r}\text { Contacts of } \\
\text { coronavirus infection }\end{array}$ & $\begin{array}{l}\text { - Fear of falling critically ill and death } \\
\text { - Fear \& guilt of transmitting infection to others } \\
\text { - Boredom and frustration due to isolation }\end{array}$ \\
\hline $\begin{array}{r}\text { Individuals infected } \\
\text { with coronavirus } \\
\text { infection }\end{array}$ & $\begin{array}{l}\text { - Fear of falling critically ill and death } \\
\text { - Fear \& guilt of transmitting infection to others } \\
\text { - Boredom and frustration due to isolation }\end{array}$ \\
\hline $\begin{array}{l}\text { Individuals declared } \\
\text { "recovered" from } \\
\text { coronavirus infection }\end{array}$ & $\begin{array}{l}\text { - Fear of getting rejected in the society } \\
\text { - Anticipation of possible physical complication in long term }\end{array}$ \\
\hline
\end{tabular}

their ongoing psychiatric illness due to the lockdown state this pandemic has imposed, leading to an increase in the risk of relapse. Simultaneously, the comorbid medical conditions in these patients could also increase their vulnerability to acquire COVID-19, thereby further worsening their mental health due to the stress [5]. This group of population needs a special address. During the COVID-19 pandemic, additional issues that could increase psychological trauma are other natural disasters. There is an urgent need to deal with the mental health issues among such populations, with additional trauma-focused care [10]. A recent study from China revealed that the prevalence of post-traumatic stress disorder (PTSD) symptoms in the areas worst affected by COVID is high. These PTSD symptoms are more prominent in females involving the domains of cognition, mood, arousal, and reexperiencing the symptoms. Poor sleep quality was found to be a strong predictor of experiencing PTSD symptoms [7]. Emerging evidences support the possible role of neurobiological changes (immunological, demyelinating, degenerative) that attribute to development of psychiatric manifestations during this COVID-19 pandemic [11].

Group intervention, though an effective technique to deal with the mental health issues in situations like natural calamities and disasters, would be a non-rational measure as of now, due to the urgent need for social distancing to limit the spread of coronavirus infection. In such critical situations, online intervention and crisis helpline may provide a reasonable solution to deliver person-centered care. These forms of mental health services also become important as the mental health needs of various groups of population are different, especially during the COVID-19 pandemic. If group intervention is to be considered, then there is a need to form the group based on common mental health needs, considering the scarcity of manpower. The mental health needs of a vulnerable population (elderly, those with medical co-morbidity, children, and marginalized population), healthcare workers, police personals, and patients with preexisting mental health difficulties are diverse. Management protocols that give general directions may not be fit to the individual mental health needs. The clinicians need to consider the individual needs (Fig. 2) of the clients and allowed them to do appropriate interventions as per the need within permissible limits of the law and practice guidelines. At the same time, the government should allow the clinicians to use their clinical judgment to recommend treatments as per the genuine need of the patient. There is an urgent need to prepare to face the forthcoming challenge in resource-scarce settings and the light of the person-centered care model.

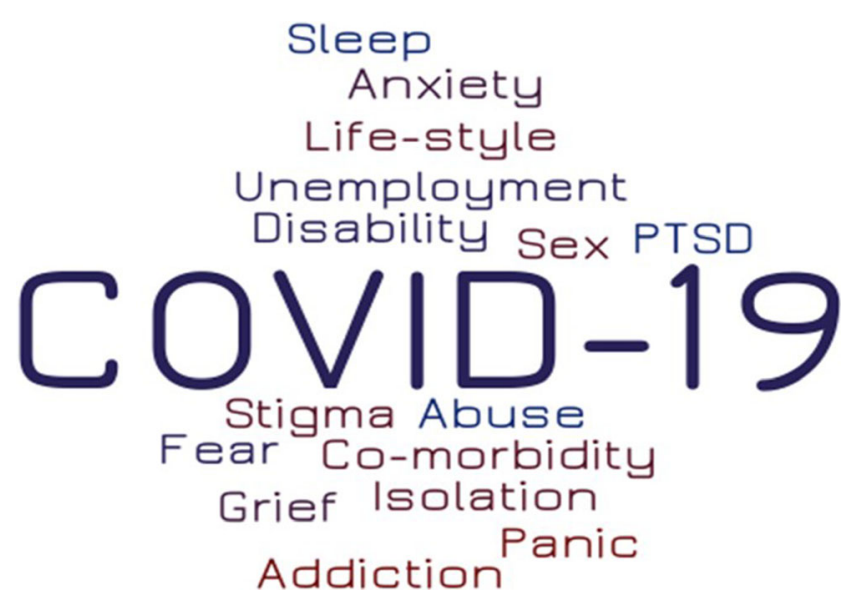

Fig. 2 Person-specific mental healthcare needs during the COVID-19 pandemic 


\section{Compliance with Ethical Standards}

Conflict of Interest The authors declare that they have no conflict of interest.

Human and Animal rights Not applicable.

\section{References}

1. Chen Q, Liang M, Li Y, Guo J, Fei D, Wang L, et al. Mental health care for medical staff in China during the COVID-19 outbreak. Lancet Psychiatry. 2020;7(4):e15-6. https://doi.org/10.1016/ S2215-0366(20)30078-X.

2. Das N. Psychiatrist in post-COVID-19 era - are we prepared? Asian J Psychiatr. 2020;102082:102082. https://doi.org/10.1016/j. ajp.2020.102082.

3. Duan L, Zhu G. Psychological interventions for people affected by the COVID-19 epidemic. Lancet Psychiatry. 2020;7(4):300-2. $\mathrm{https}$ ://doi.org/10.1016/S2215-0366(20)30073-0.

4. Jacobsen KH. Will COVID-19 generate global preparedness? Lancet. 2020;395:1013-4. https://doi.org/10.1016/S01406736(20)30559-6.

5. Kavoor AR. Covid-19 in people with mental illness: challenges and vulnerabilities. Asian J Psychiatr. 2020;102051. https://doi.org/10. 1016/j.ajp.2020.102051.

6. Lancet T. COVID-19: protecting health-care workers. Lancet. 2020;395(10228):922. https://doi.org/10.1016/S0140-6736(20) 30644-9.
7. Liu N, Zhang F, Wei C, Jia Y, Shang Z, Sun L, et al. Prevalence and predictors of PTSS during COVID-19 outbreak in China hardest-hit areas: gender differences matter. Psychiatry Res. 2020;287:112921. https://doi.org/10.1016/j.psychres.2020.112921.

8. Mohindra R, Ravaki R, Suri V, Bhalla A, Singh SM. Issues relevant to mental health promotion in frontline health care providers managing quarantined/isolated COVID19 patients. Asian J Psychiatr. 2020. https://doi.org/10.1016/j.ajp.2020.102084.

9. Roy D, Tripathy S, Kar SK, Sharma N, Verma SK, Kaushal V. Study of knowledge, attitude, anxiety \& perceived mental healthcare need in Indian population during COVID-19 pandemic. Asian J Psychiatr. 2020. https://doi.org/10.1016/j.ajp.2020. 102083.

10. Shi W, Hall BJ. What can we do for people exposed to multiple traumatic events during the coronavirus pandemic? Asian $J$ Psychiatr. 2020. https://doi.org/10.1016/j.ajp.2020.102065.

11. Troyer EA, Kohn JN, Hong S. Are we facing a crashing wave of neuropsychiatric sequelae of COVID-19? Neuropsychiatric symptoms and potential immunologic mechanisms. Brain Behav Immun. 2020;87:34-9. https://doi.org/10.1016/j.bbi.2020.04.027.

12. Walton M, Murray E, Christian MD. Mental health care for medical staff and affiliated healthcare workers during the COVID-19 pandemic. Eur Heart J Acute Cardiovasc Care. 2020;9:241-7. https:// doi.org/10.1177/2048872620922795.

Publisher's Note Springer Nature remains neutral with regard to jurisdictional claims in published maps and institutional affiliations. 